\title{
Frontières
}

BERCHOUD, Joseph (dir.), Ultime solidarité.

L'accompagnement à la mort. Paroles de témoins, Turin, Éditions du Signe, 2003, 327 p.

\section{Jean-Jacques Lavoie}

Volume 16, numéro 2, printemps 2004

URI : https://id.erudit.org/iderudit/1074135ar

DOI : https://doi.org/10.7202/1074135ar

Aller au sommaire du numéro

Éditeur(s)

Université du Québec à Montréal

ISSN

1180-3479 (imprimé)

1916-0976 (numérique)

Découvrir la revue

Citer ce compte rendu

Lavoie, J.-J. (2004). Compte rendu de [BERCHOUD, Joseph (dir.), Ultime solidarité. L'accompagnement à la mort. Paroles de témoins, Turin, Éditions du Signe, 2003, 327 p.] Frontières, 16(2), 105-105. https://doi.org/10.7202/1074135ar d'utilisation que vous pouvez consulter en ligne.

https://apropos.erudit.org/fr/usagers/politique-dutilisation/ 
Il n'y a pas d'expérience plus solitaire que de mourir, car la mort, bien qu'elle soit universelle, garde mystérieusement pour chacun un caractère singulier, privé et incommunicable. Personne ne peut faire, à la place de celui qui agonise, l'ultime pas du dernier voyage. Celui qui meurt, même s'il est accompagné par des êtres qui lui sont les plus chers, est donc fondamentalement seul. Pourtant, malgré cette solitude irréfragable, le minimum en fin de vie, c'est de pouvoir mourir accompagné. Or, I'accompagnement de celui qui va mourir ne va pas de soi.

Pas plus que l'accompagnement des endeuillés. La générosité et la bonne volonté ne suffisent pas. Une formation de base est donc obligatoire. C'est ce dont témoigne ce livre qui aborde quatre grands thèmes: "Paroles de soignants", "Spiritualité et religions", "Le moment de la mort et des funérailles», et «Vivre le deuil ».

Dirigé par Joseph Berchoud, chargé des relations publiques aux Pompes funèbres générales à Paris, et préfacé par l'Abbé Pierre, l'ouvrage est donc un collectif à l'image même de ceux qui prennent en charge d'accompagner les mourants et les endeuillés. II réunit 26 contributions provenant d'auteurs issus de divers milieux professionnels. Près du tiers du livre est rédigé par des soignants, qui sont devenus les premiers responsables de l'accompagnement, les garants du savoir-faire et du savoir-être. Bien entendu, ces professionnels de la santé, qu'ils soient médecin, infirmière, aide-soignant ou professeur, ne sont pas les seuls à prendre la parole, car la mort n'est pas d'abord un événement médical. Psychologues et psychanalystes interviennent également, aussi bien en relation avec les mourants que les endeuillés. La parole est aussi donnée à des prêtres et des pasteurs, qui semblent toujours jouer un rôle important dans les milieux hospitaliers, un rôle qui n'est plus confiné aux strictes affaires de sacristie. Quelques chapitres sont rédigés par des bénévoles qui, n'étant porteurs d'aucune fonction officielle, rappellent que la mort n'est pas seulement l'affaire des professionnels de la santé physique, psychologique et spirituelle, mais aussi de la société. Enfin, une partie importante du livre est réservée aux personnels responsables des soins au défunt : thanatopracteur, conseiller funéraire, chargé des relations aux pompes funèbres, conservateur de cimetière et responsable de crématorium. Leurs témoignages illustrent parfois avec éloquence qu'ils jouent, eux aussi, un rôle non négligeable dans l'accompagnement des endeuillés.

Ce collectif, qui est de valeur très inégale, s'adresse à quiconque est intéressé, non pas à lire des recettes toutes faites, mais à se laisser interpeller par des témoignages et, plus rarement, des réflexions de ceux qui se sont mis à l'école de l'humilité et du dépouillement.

Jean-Jacques Lavoie 